\title{
Vaccine development in Canada
}

los

N THIS ISSUE OF THE JOURNAL, SCHEIFELE AND TINGLE (PAGE 79) share some insights and experiences gained over the past five years in the development of a Vaccine Evaluation Centre in Vancouver. Their paper reviews the current status of the rapidly changing arena of childhood vaccinations, describes the pre-licensure and post marketing surveillance requirements for vaccinations, as well as specifically providing their perspectives of successes and problems with development of the centre.

The profound impact of vaccination on morbidity and mortality from communicable diseases is incontrovertible. Medical journals of the 19th century are replete with articles describing diphtheria. Today, most infectious diseases physicians have never seen a case of diphtheria. A contagious diseases text book written at the turn of the century discusses only seven infectious diseases: smallpox, chickenpox, scarlet fever, measles, rubella, typhus fever and diphtheria (1) - four of these have either been eradicated or are uncommon today, virtually solely due to immunization. The dramatic decrease in poliomyelitis, rubella, rubeola or occupationally acquired hepatitis B infection following introduction of effective vaccines is within the living memory of most infectious diseases physicians. The former 'common' contagious diseases of childhood are, in many cases, disappearing diseases that are a medical oddity when identified. Major problems with disease prevention for many contagious diseases now are not related to efficacy of vaccine, but to problems in vaccine delivery.

Research and progress in potential vaccines is overwhelming. Many products are currently at different stages of development, and virtually every infectious agent is being considered from the viewpoint of possible vaccine development. We are close to licensing a varicella/zoster vaccine, hepatitis A vaccine and others. Newer vaccines with potentially less toxicity or greater efficacy, such as the acellular pertussis vaccine and attenuated typhoid vaccine, improve on older agents. Over the next decade, both rubeola and poliomyelitis could disappear with expanded immunization programs. Other diseases, such as hepatitis A, varicella/ zoster infection and hepatitis B, could be targeted for eradication as vaccines become available and vaccination programs are expanded. The remarkable impact of vaccination on the occurrence of infectious diseases can be anticipated to continue.

What is the role of the Canadian health care system and Canadian investigators in this complex, expanding and stimulating scenario? Participation by Canadian investigators in this important and rapidly advancing field is desirable. In addition, vaccines should be evaluated and used to provide optimal benefits to Canadians and the Canadian health care system. These issues cross the boundaries of the academic community, the medical community, industry and politics. It seems desirable to retain resources for these investigations in Canada and seems likely that input relevant to the Canadian health care system early in the development process should improve use of vaccines in this country. Specific benefits to be achieved by promoting this research in Canada, however, are difficult to quantify at this stage.

The early development of a Vaccine Centre in Vancouver is one step to promote Canadian involvement in the vaccine arena. The multifaceted approach and focus on clinical rather than basic research in the early years of the centre has allowed it to throw a wide net. with involvement in studies with relatively immediate clinical accessability. The potential for promoting large scale phase III trials in Canadian populations to allow vaccine decisions to be based on studies relevant to our population is particularly attractive. Future successes of the Vaccine Centre would, hopefully, include the completion of such studies.

The major difficulties identified by the authors in establishing the centre relate to funding. All researchers can appreciate the difficulties in obtaining funding in the current climate of extreme cost constraint. The Vaccine Centre has been developed primarily with industrial funding, with some regional funding. A central role for industry funding is, perhaps, defensible, as industry is anticipating a profit following marketing of the products.

Several important considerations must be acknow- 
ledged, however, with respect to industry sponsorship. These are relevant not only to vaccine-related research but other academic/industry collaborations. The first, as Tingle and Scheifele note, is that many pharmaceutical or vaccine producing companies are multinationals with head offices outside Canada. This means that the Canadian offices are 'branch plants'. The degree of autonomy of the Canadian office varies with different companies. The necessity for national projects to be reviewed and approved at the international level to ensure compatibility with the international development program is understandable from industry's prospective, but time delays and limitations in scope may be detrimental to Canadian research and investigators.

The second important point is to acknowledge the differing goals of the participants in academic/industrysponsored research. The goal of industry is to generate profits, usually within the short term. Thus, industrysponsored studies are tailored to obtain data required for licensing and marketing of products. The longer term goals of characterizing the impact of a given vac- cine, antibiotic or other product on the health of the Canadian population or the Canadian medical system in a competitive market are lost in industry priorities. It is not realistic to expect industry to support these goals. Occasionally, clinical studies may be developed that meet the needs of industry, academia and the health care system, but few studies achieve this goal. As Tingle and Scheifele point out, a nonindustry sponsor, preferably Government, as has been demonstrated to be effective in other countries, is needed. This would allow development of studies outside industry imperatives to optimize the effective use of vaccines in our society.

\section{REFERENCES}

1. Welch WM, Schanberg JF. Acute Contagious Diseases. Philadelphia: Lea Brothers and Co, 1905. 


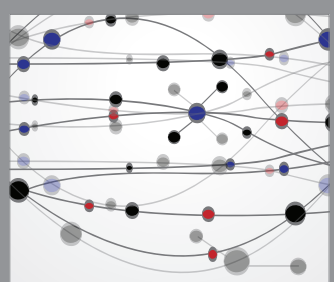

The Scientific World Journal
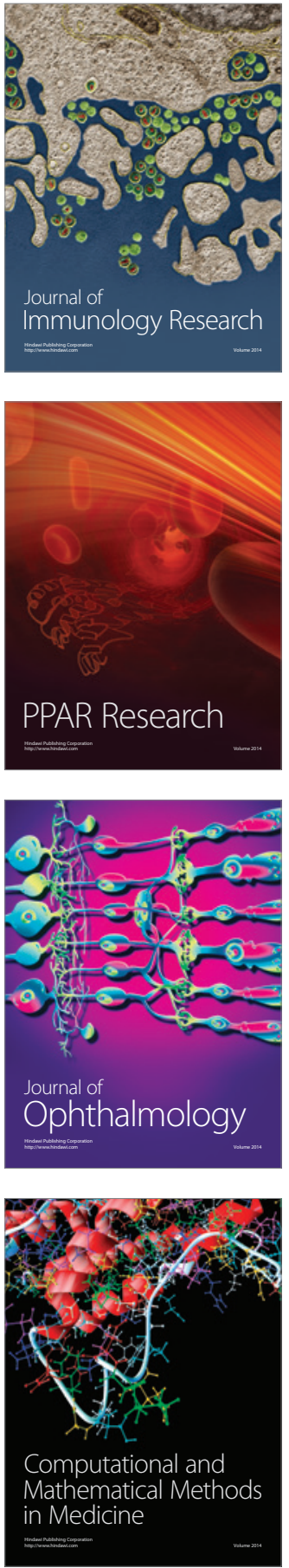

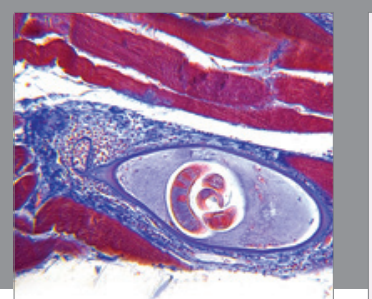

Gastroenterology Research and Practice

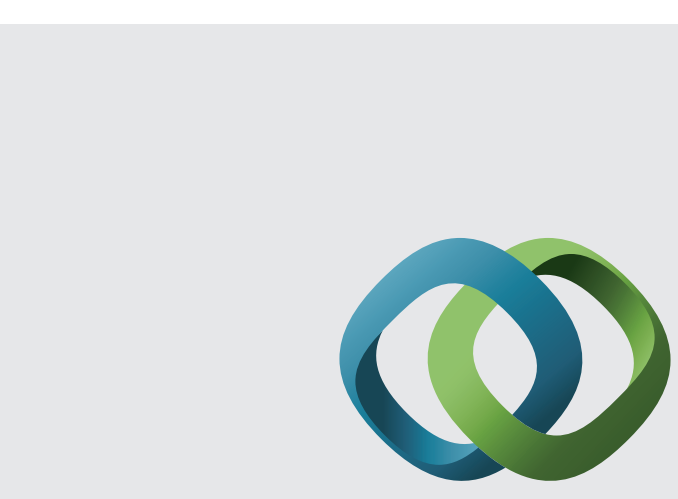

\section{Hindawi}

Submit your manuscripts at

http://www.hindawi.com
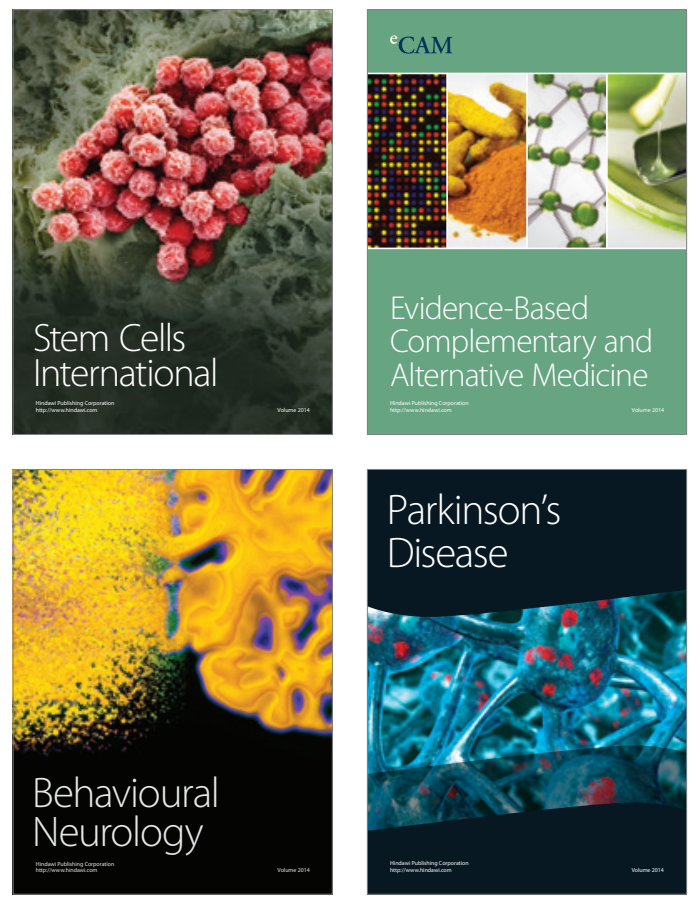
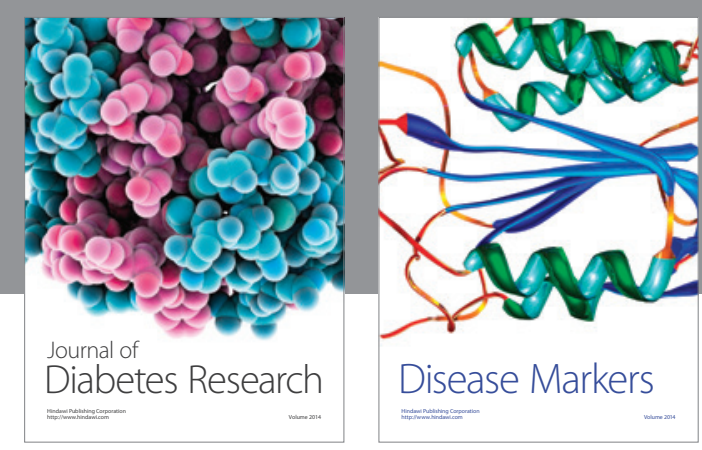

Disease Markers
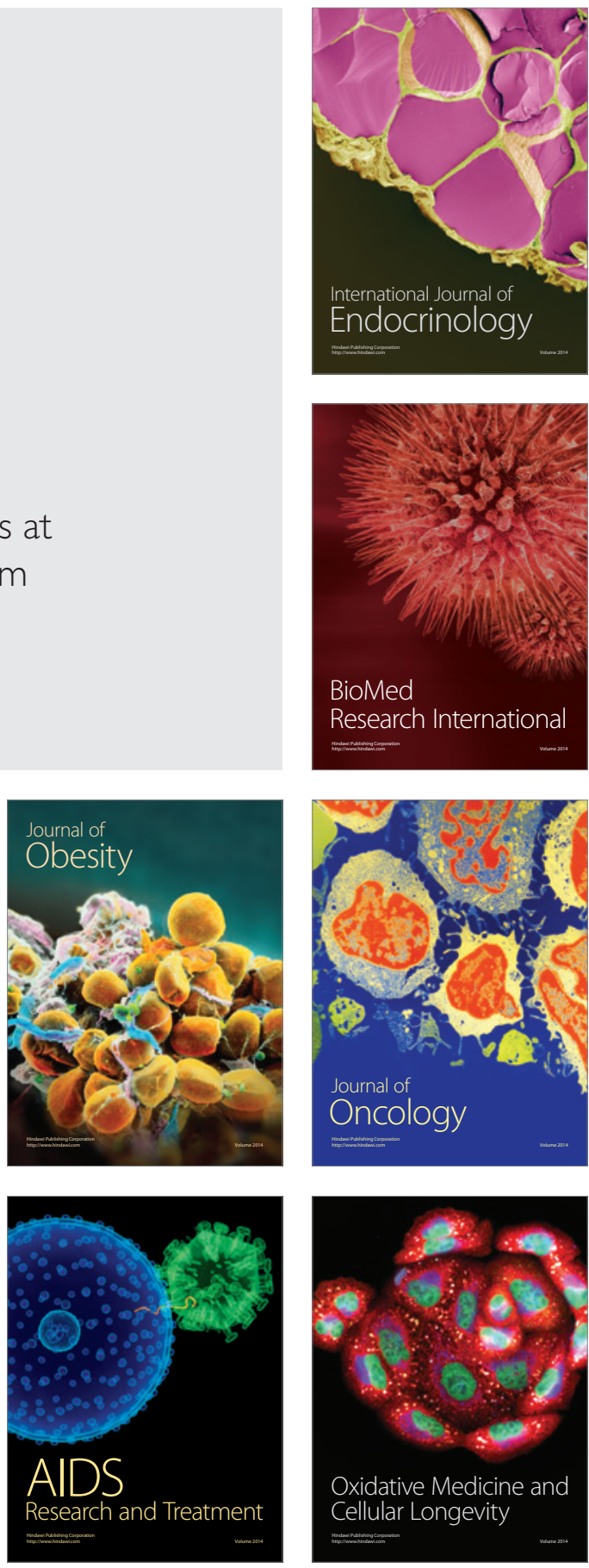